Federal Reserve Bank of Minneapolis

Research Department

\title{
Consumer Bankruptcy: A Fresh Start
}

\author{
Igor Livshits, James MacGee, \\ and Michele Tertilt*
}

Working Paper 617

Revised January 2003

\begin{abstract}
American consumer bankruptcy provides for a Fresh Start through the discharge of a household's debt. Until recently, many European countries specified a No Fresh Start policy of life-long liability for debt. The trade-off between these two policies is that while Fresh Start provides insurance across states, it drives up interest rates and thereby makes life-cycle smoothing more difficult. This paper quantitatively compares these bankruptcy rules using a life-cycle model with incomplete markets calibrated to the U.S. and Germany. A key innovation is that households face idiosyncratic uncertainty about their net asset holdings (expense shocks) and labor income. We find that expense uncertainty plays a key role in evaluating consumer bankruptcy laws.
\end{abstract}

*Livshits, MacGee, University of Western Ontario; Tertilt, University of Minnesota. We thank Michele Alexoupoulos, V.V. Chari, Russ Cooper, Dean Corbea, Larry Jones, Tim Kehoe, Narayana Kocherlakota, Ellen McGrattan, Ed Prescott, Victor Rios-Rull, Ben Bridgman, Adam Copeland, Margaret Ledyard, Ron Leung, Juan Rubio, Juan Sole, and seminar participants at the University of Minnesota, the Federal Reserve Bank of Minneapolis, the Federal Reserve Bank of Atlanta, the University of Toronto, the University of Western Ontario, Simon Fraser University, Pennsylvania State University, Southern Methodist University, Guelph University, York University, Midwest Macro Meetings, Canadian Macro Study Group, and the SED Meetings for helpful comments. The authors are grateful to the Federal Reserve Bank of Minneapolis for their support during the writing of this paper. The views expressed herein are those of the authors and not necessarily those of the Federal Reserve Bank of Minneapolis or the Federal Reserve System. 


\section{Introduction}

This paper quantitatively analyzes the impact of different consumer bankruptcy arrangements for unsecured debt. The evaluation of consumer bankruptcy laws involves an assessment of the magnitude of two opposing forces. On the one hand, consumer bankruptcy provides insurance to households who suffer from bad luck - such as divorce, job loss or medical problems. The easier it is for consumers to discharge some (or all) of their debt, the greater the insurance. The price of increased insurance, however, is an increased interest rate for borrowing. In other words, consumer bankruptcy laws can help consumers smooth their consumption across states at the cost of distorting their ability to smooth over time. This trade-off implies that any evaluation of bankruptcy rules must evaluate the quantitative costs of credit market distortions and the extent of "bad luck".

A quantitative analysis of alternative bankruptcy rules is particularly relevant for two reasons. First, different countries have adopted very different consumer bankruptcy rules. Second, there has been considerable public debate - both in the U.S. and in European countries - on the relative merits of alternative consumer bankruptcy rules. Recent debate in the United States has focused on whether American bankruptcy rules are too lenient. This debate has been motivated by the increase in consumer bankruptcies from less than 250,000 cases in 1978 to about 1,250,000 two decades later (see Sullivan, Warren, and Westbrook (2000) for more details). This has led to proposed legislation which would make it more difficult for households to declare bankruptcy.

Public debate in many European countries has moved in the opposite direction. Up until the 1990's consumer bankruptcy laws were non-existent in Germany and most European countries (Alexopoulos and Domowitz (1998), Niemi-Kiesilainen (1997)). The inability to declare bankruptcy meant that unlucky debtors could not discharge their debt, remaining liable for past obligations for thirty years to life. More recently, the lifelong liability for debts has been interpreted as a problem in the European debate, and many have suggested that Europe should adopt many of the elements of American bankruptcy law. This has led to some limited reforms, which are reflected in the 1999 amendments to the German insolvency law (similar reforms have occurred in other European countries). While the new law allows for a partial discharge after a 7 year payment plan, an immediate discharge of debt such as that granted under Chapter 7 in the U.S. is not possible.

A related question is the effect alternative bankruptcy rules have on labor supply decisions. A key argument that has been advanced in favor of the "fresh start" provisions is that providing debtors with a fresh start provides incentives for consumers to work hard. This argument in favour of the "fresh start" doctrine is succinctly summarized in a U.S. Supreme Court Ruling in 1934:

"One of the primary purposes [...] is to relieve the honest debtor from the weight of oppressive 
indebtedness, and to permit him to start afresh [...]. From the viewpoint of the wage earner, there is little difference between not earning at all and earning wholly for a creditor [...] The new opportunity in life and the clear field for future effort [...]"

In other words, one of the objectives of bankruptcy is to create the proper incentives for consumers with large debts to work.

To address these questions, we study a hetereogeneous agent life cycle model. Each period, households decide what fraction of their time to allocate to working and how to allocate their income over time. Households also decide on whether or not to file for bankruptcy, given the specified bankruptcy rules. These rules specify both the amount that can be garnished from households who default on debts and whether discharge of debt is granted. Households can borrow (and save) via one period non-contingent bonds with perfectly competitive financial intermediaries. Intermediaries are able to observe households current income, current level of borrowing and age when making loans. An equilibrium result is that the price of debtors bonds' varies with their current income, age and level of borrowing.

We make these modelling choice for several reasons. First, we are interested in the role of bankruptcy. This leads us to look at a model where household's ability to self-insure is limited. Second, we wish to evaluate the effects that bankruptcy rules have on labor supply. This leads us to look at a life cycle model where agents may choose to exit the labor force in response to high debt levels. Finally, we wish to have financial institutions which are able to condition loans on observable characteristics of borrowers. It should be noted that in this paper we abstract from durable goods and focus solely on the market for unsecured consumer credit.

An important question is how to model the cost of defaulting. We incorporate three costs that are frequently mentioned in the literature. One punishment is future exclusion from credit markets. In our model, this corresponds to the inability to borrow and save within the default period. We do not exclude agents from the credit market for any further periods, because, although bankruptcy shows up on a consumer's credit report for 10 years, many banks specialize in lending to former bankrupts, and therefore the exclusion does not seem to be severe. The second punishment is a transaction cost on consumption incurred by the bankrupt consumer during the default period. The interpretation of this quasi consumption tax for bankrupts is that the inability to use credit makes consumption more time-consuming and inefficient. For example, it may be harder to rent an apartment with a bad credit record. We assume that this punishment is in effect only for the period in which bankruptcy is declared. The last punishment is that part of the consumer's income may be seized when bankruptcy is declared. We are aware that a chapter 7 bankruptcy in the U.S. precludes any seizure of income, even during the default period. We nevertheless use a garnishment technology in our model as a proxy for several other payments a bankrupt debtor is forced 
to make. ${ }^{1}$

Our contributions are threefold. First, we find that the welfare implications of different bankruptcy rules are sensitive to the type and size of uncertainty incurred. We quantify two types of household uncertainty: income and expense uncertainty. Income uncertainty refers to variations in the earnings of households over time, and is the primary source of uncertainty considered in the existing literature. Expense shocks refer to uninsured medical bills, divorce costs or unplanned children. These shocks are frequently cited by bankrupts as the cause of their bankruptcy. We find that expense shocks play an important role in the evaluation of alternative bankruptcy rules. Using parameters calibrated to match the U.S. economy, we find that if we ignore expense shocks, then a bankruptcy arrangement that severely limits the discharge of debt is better than one where discharge is easy. However, introducing expense shocks calibrated to U.S. data can lead one to conclude that fresh start provisions are welfare improving compared to no-fresh start. This implies that ignoring expense shocks may lead to the wrong policy recommendations.

Our second key conclusion is closely related. This is that the difference in consumer bankruptcy laws between Germany and the United States is consistent with the different levels of uncertainty faced by households in the two countries. As we document, the volatility of both household income and expenses are lower in Germany, than in the United States. In our numerical experiments, we find that a fresh start bankruptcy rule yields higher ex ante welfare in the United States, but not in Germany.

Our third finding is that Fresh Start has a very small effect on effort decisions compared to No Fresh Start. Indeed, in our numerical experiments, households in the No Fresh Start who declare bankruptcy generally work harder than their counterparts in Fresh Start. This is due to two effects. First, since it is costly to remain in bankruptcy, households work harder so as to pay off their debt as soon as possible and exit bankruptcy. Second, Fresh Start tilts life time work effort decisions forward, since the stricter borrowing constraints lead to higher work effort of young households under Fresh Start than under No Fresh Start.

Despite the extensive policy debates on the merits of different bankruptcy laws, relatively little work has been done to quantify the uncertainty households face and the effects of alternative consumer bankruptcy provisions. At a theoretical level, the basic trade-offs implied by bankruptcy rules in exchange economies with incomplete markets are well understood

\footnotetext{
${ }^{1}$ At least three different payments come to mind. First, the "good faith" requirement in U.S. bankruptcy law usually precludes consumers from requesting a discharge of debt immediately after receiving a loan. This means that at least a fraction of one's debt has to be repaid before bankruptcy can be filed. Secondly, assets can be seized during a chapter 7 bankruptcy. Part of the consumption of a 5-year model period could be reinterpreted as durable goods accumulated during that period, which are seized when a bankruptcy is declared. Last, a bankrupt has to pay the court filing fee, legal fees, plus allocate a substantial amount of time to completing paperwork required for filing.
} 
(see Zame (1993) or Dubey, Geanakoplos, and Shubik (2000)). ${ }^{2}$ On the one hand, bankruptcy weakens agents' ability to commit to repaying borrowing in the future which limits their ability to smooth consumption across time. Conversely, in incomplete markets environments, bankruptcy increases households' ability to smooth across states as it introduces contingencies into non-contingent debt contracts. Thus, bankruptcy can increase welfare by increasing households' ability to smooth across states. What our approach adds to this literature is a quantitative assessment of these two forces for specific bankruptcy rules.

Recently, several papers have analyzed the effects of alternative bankruptcy rules. Li (2001) and Repetto (1998) examine two period models where households face uncertainty about their productivity in the second period of their life. Athreya (2000) and Athreya (2002) build on earlier work by Aiyagari (1994) and others to quantitatively analyze the effects of bankruptcy laws in an exchange economy where infinitely lived households face idiosyncratic income uncertainty. Markets are incomplete, as agents can save/borrow only via one period bonds. In the equilibrium, a constant fraction of all agents default. Li and Sarte (2002) introduce production and a partially exempt asset into this framework and analyze the consumers choice of Chapter 7 versus 13. In contrast to Athreya (2002), they find that eliminating the bankruptcy option is welfare reducing in the U.S. However, they conclude that amending the current U.S. bankruptcy code to allow for means testing would lead to small welfare gains.

A crucial difference between these papers and our work is the modelling of bond prices. Athreya, Li, Li and Sarte and Repetto all assume that all agents can borrow at the same interest rate, which implies that intermediaries could make positive profits by deviating from the equilibrium allocation. To get around this implausible outcome, we allow interest rates to depend on the type of an agent and on the amount borrowed.

The only other paper we know of that also allows interest rates to vary with borrowers' characteristics is Chatterjee, Corbae, Nakajima, and Rios-Rull (2001). The distinction between our work and theirs is threefold. First, we address very different questions. Their objective is to build a model that explains current bankruptcy levels in the U.S. We are interested in comparing different bankruptcy rules. Moreover, we are interested in the effect of Fresh Start on work effort decisions. We allow for labor leisure choices, while they have an exogenous income process. Second, we focus on the quantitative importance of wealth shocks associated with uninsured medical expenses, divorce and unexpected children. Finally, our model also differs from theirs in several modelling aspects. We use a life-cycle model, whereas Chatterjee, Corbae, Nakajima, and Rios-Rull (2001) employ an infinitelylived consumer model.

\footnotetext{
${ }^{2} \mathrm{~A}$ somewhat related literature has focused on the implications of economies with limited enforcement, see Kehoe and Levine (1993) and Kocherlakota (1996).
} 
The paper is organized as follows. Some background on bankruptcy laws is given in section 2. The details of the model are explained in Section 3. Section 4 sets up the consumer's problem formally, and defines equilibrium. Section 5 describes the calibration. Results are presented in Section 6, and Section 7 concludes.

\section{Consumer Bankruptcy in the U.S. and Germany}

This section provides some background information on the details of American consumer bankruptcy law, on the characteristics of a typical bankrupt, as well as on the main causes as reported by the bankrupt debtors.

\section{A. Consumer Bankruptcy in the U.S.}

American households can choose between two bankruptcy procedures: Chapter 7 and Chapter 13. Under Chapter 7, all unsecured debt is discharged in exchange for noncollateralized assets above an exemption level. However, debtors are not obliged to use any of their future income to repay debts. Debtors who file under Chapter 7 are not permitted to refile under Chapter 7 for six years, although they may file under Chapter 13. Approximately 70 percent of consumer bankruptcies are filed under Chapter 7. Filers must pay the bankruptcy court filing fee and the cost of legal advice. The current cost of filing is $\$ 200$. Sullivan, Warren, and Westbrook (2000) report that legal fees typically range from $\$ 750$ to $\$ 1,500$. In addition, a debtor filing for bankruptcy has to submit a detailed list of all creditors, amounts owed, source, amount, and frequency of income, all assets and monthly living expenses. A typical chapter 7 bankruptcy takes about 4 months from start to completion.

Chapter 13 permits debtors to keep their assets in exchange for a promise to repay part of their debt over the next 3 to 5 years. The debtors plan must repay unsecured creditors at least as much as they would have received under a Chapter 7 filing. The plan must be confirmed by the bankruptcy judge, but creditors cannot block the plan. In order to qualify for Chapter 13, individuals must have a regular income and their debts must be within prescribed limits (secured debts must be less than $\$ 807,000$ and unsecured debt must be less than $\$ 270,000)$.

A typical bankrupt is a white lower middle-class woman in her thirties with an extremely high debt-to-income ratio. Sullivan and Warren (1999) report that $40 \%$ of all bankruptcies were declared by women, $33 \%$ by men, and $28 \%$ were joint filings. Sullivan, Warren, and Westbrook (2000) report that about $70 \%$ of all bankruptcies were declared by whites, while white people make up only $65 \%$ of the American population. On average, bankrupt households are 30-50\% poorer than the average household, which means that they are still well above poverty level. However, debt-to-income ratios are well above average. Sullivan, Warren, and Westbrook (2000) report an average debt-to-income ratio of 2.8 for bankrupts in 1997, compared to an overall ratio of 0.8 . The age distribution of bankrupts 
reveals that default rates are highest for households with a middle aged head.

The main cause of bankruptcy is unexpected shocks to income and expenses. The main source of unexpected changes in income is job loss. Sullivan, Warren, and Westbrook (2000) analyze a survey of 1991 bankruptcy filings, and find that $67.5 \%$ of fillers reported the main cause of their bankruptcy to be the loss of a job (multiple responses were permitted). There are two primary sources of unexpected expenses: medical expenses and family problems (particularly divorce). Sullivan, Warren, and Westbrook (2000) report that family issues such as divorce $(22.1 \%)$, and medical expenses (19.3\%) were cited as the primary cause of bankruptcy. ${ }^{3}$ Work by Jacoby, Sullivan, and Warren (2000) suggests that medical problems can account for an even larger fraction of American bankrupts. Based on a study of 1,492 bankruptcies in 1999, they find that $34 \%$ of bankrupts owed substantial medical debt, and that $46 \%$ of filers report either a medical reason or substantial medical debt. Domowitz and Sartain (1999) also find that medical debt plays a significant role in consumer bankruptcy, as their findings suggest that medical debt alone can account for roughly 30 percent of U.S. consumer bankruptcies in 1994.

\section{B. Consumer Bankruptcy in Germany}

No consumer bankruptcy law existed in Germany prior to 1999. Consumers were liable for any debt until the end of their lives. ${ }^{4}$ If a borrower defaulted on her payments, creditors could repossess her assets and garnish her wages. The bankrupcty court also specifies a rollover interest rate which is used to determine the new debt a consumer owes if he cannot pay his debts at a given time.

There is no official measure of the number of German households in default prior to 1999. The estimated number of wage garnishments was 200,000 households (or about 0.6 percent). The reasons named are similar to those mentioned in the U.S., with unemployment, divorce, and illness being among the top causes (Rath (1996)).

\section{The Environment}

We consider an overlapping generations model of households who live for $J$ periods. Each generation is comprised of a continuum of households of measure 1. All households are ex-ante identical. They maximize their life-time discounted utility from consumption and leisure. Households face idiosyncratic uncertainty, but there is no aggregate uncertainty. Markets are incomplete: the only assets in this economy are person-specific one-period non-contingent bonds. A crucial element of the model is the households option to declare

\footnotetext{
${ }^{3}$ Repetto (1998) reports data from the 1996 PSID with similar results.

${ }^{4}$ A consumer bankruptcy law came into effect in January, 1999, which allows for the discharge of debt after a 7-year payment schedule approved by the court. In this paper we focus on the situation in Germany before 1999.
} 
bankruptcy.

\section{A. Households}

Each household has preferences defined over a consumption good and effort. Preferences can be represented by:

$$
\sum_{j=1}^{J}\left(\prod_{i=1}^{j-1} \beta_{i}\right) u\left(c_{j}, 1-h_{j}\right)
$$

where $\beta_{i}$ is the period discount factor of a household of age $i, c_{j}$ and $h_{j}$ are consumption and effort respectively, at age $j$, and $u(\cdot)$ is a $C^{2}$, increasing and concave function.

The household can choose any work effort in the unit interval. An agent of age $j$ is endowed with $\bar{e}_{j}$ efficiency units of labor. Her output is determined by productivity, work effort, and the labor endowment. Output of an age $j$ consumer is $y_{j}=z_{j} \bar{e}_{j} h_{j}$, where $z_{j}$ is the household's productivity at age $j$. The productivity parameters $z$ are a random variable with finite support. Productivity is modelled as a Markov chain with an age independent transition matrix $\Pi\left(z^{\prime} \mid z\right)$. The productivity of an age 0 consumer is drawn from the stationary distribution.

Households face a second type of uncertainty: They may be hit with an idiosyncratic expense shock $\kappa \geq 0, \kappa \in K$, where $K$ is the finite set of all possible expense shocks. The probability of shock $\kappa$ is denoted $\pi(\kappa)$. An expense shock directly changes the net asset position of a household. Expense shocks are independently and identically distributed, and are independent of income shocks.

\section{B. Financial Markets}

The borrowing and lending market is perfectly competitive. Financial intermediaries accept deposits from savers and make loans to borrowers. Loans take the form of one period bond contracts. The face value of these loans is denoted by $d$. Note that $d$ is the amount that is promised to be repaid next period, not the amount received today. We use the convention that $d>0$ denotes borrowing, and $d<0$ denotes savings. Loans are non-contingent as the face value of the loan is not contingent on the realization of any variable. However, the bankruptcy/default option introduces a partial contingency, as households have the option of lowering the face value of their debt by filing for bankruptcy.

When making loans, intermediaries observe the total level of borrowing, the current productivity shock, and the age of the borrower. Thus, the interest rate for borrowers can depend upon age, debt level, and current productivity. Let $q^{b}(d, z, j)$ be the price of a loan issued to a household of age $j$, with a current productivity shock $z$, and total debt $d$.

Intermediaries solve a static problem. They maximize expected profits every period. They incur a transaction cost $\tau$ of making loans, which is proportional to the size of the loan. 
In equilibrium, perfect competition assures that intermediaries earn zero expected profits on all loans. This implies that the expected value of repayments must be equal to the cost of the loan to the intermediary. Perfect competition also implies that in equilibrium, cross subsidization of interest rates across different types of borrowers will not occur. Further, this means that the interest rate paid to savers does not depend upon the level of savings and is equal to the exogenous risk-free bond price $q^{s}$.

\section{Bankruptcy}

A household can declare bankruptcy. A bankruptcy rule is characterized by two elements:

1. A law of motion for the bankrupt household's debt.

2. A garnishment rule that specifies the amount of a household's assets and earnings that can be seized by creditors.

In addition to losing the seized income specified in the bankruptcy rule, bankrupt debtors face two further punishments during the default period. First, bankrupts pay a transaction cost $\lambda$, proportional to consumption expenditures during the default period. Secondly, bankrupts cannot save or borrow during the default period.

We consider two laws of motion for the debt of bankrupt households. The first law of motion, which we term the fresh start system, specifies full discharge of all debts. That is, no seizure of future income is possible. This rule captures the key feature of Chapter 7 .

The second system, which we term no-fresh start, is modelled according to European bankruptcy law (up until the 1990s). No-fresh start means that the remaining debt (i.e. after seizure of income) is rolled over at a specified rate of interest. We denote this interest rate as

$\bar{r}$ and define the corresponding bond price as $\bar{q}=\frac{1}{1+\bar{r}}$. In this regime, there is no discharge of debt. The only alleviation for the bankrupt household comes from the postponement of payments and a potentially lower interest rate.

All assets of a household can be seized by creditors. We consider linear wage garnishment rules during the default period:

$$
\Gamma=[\max \{y-\bar{y}, 0\}] g
$$

where $\Gamma$ denotes the total amount garnished and transferred to creditors, $\bar{y}$ is an earnings exemption that cannot be seized and $g \in[0,1]$ is the marginal rate of garnishment. The garnishment technology is costless.

\section{Timing within the Period}

The timing within the period is as follows. At the beginning of the period, each household realizes its productivity and expense shocks. If the household receives an expense 
shock $\kappa$, then the debt of the household is increased (or savings decreased) by $\kappa$. The household then decides whether to file for bankruptcy or not and how much time to allocate to working. Work then takes place, and all earnings are deposited directly into a "bank account". If the agent has filed for bankruptcy, the amount that is garnished is deducted, and the consumer is allowed to spend the remainder.

Households who declare bankruptcy are unable to save in the period they declared bankruptcy, so they consume all of their earnings net of garnishment and transaction costs. The new debt level depends on the bankruptcy rule. Households who did not declare bankruptcy decide on their net asset holdings for the following period and their current consumption.

\section{Equilibrium}

\section{A. Consumer Problem}

We define the consumer's problem recursively. At each date, the households chooses current consumption, work effort, to default or not, and next period's debt, taking the bond price schedule as given. Let $I$ denote the consumer's decision to default.

The value function of an age $j$ consumer with debt $d$ and shock realization $(z, \kappa)$ in the Fresh Start case is

$$
\begin{aligned}
V(d, z, \kappa, j)= & \max _{c, h, d^{\prime}, I}\left\{u(c, 1-h)+\beta_{j} E V\left(d^{\prime}, z^{\prime}, \kappa^{\prime}, j+1\right)\right\} \\
\text { s.t. } & c+d+\kappa=\bar{e}_{j} z h+q^{b}\left(d^{\prime}, z, j\right) d^{\prime}, \text { if } I=0 \\
& c=(1-\lambda)\left[\bar{e}_{j} z h-\Gamma\right] \text { and } d^{\prime}=0, \text { if } I=1 \\
& c \geq 0, h \in[0,1], V(\cdot, \cdot, \cdot, J+1)=0
\end{aligned}
$$

The consumer's problem for the no-fresh start bankruptcy rule is very similar. The only difference is that the new debt level of a bankrupt debtor is not set to zero.

$$
\begin{aligned}
V(d, z, \kappa, j)= & \max _{c, h, d^{\prime}, I}\left\{u(c, 1-h)+\beta_{j} E V\left(d^{\prime}, z^{\prime}, \kappa^{\prime}, j+1\right)\right\} \\
\text { s.t. } & c+d+\kappa=\bar{e}_{j} z h+q^{b}\left(d^{\prime}, z, j\right) d^{\prime}, \text { if } I=0 \\
& c=(1-\lambda)\left[\bar{e}_{j} z h-\Gamma\right], \text { if } I=1 \\
& d^{\prime}=\max \{[d+\kappa-\Gamma], 0\} / \bar{q}, \text { if } I=1 \\
& c \geq 0, h \in[0,1], V(\cdot, \cdot, \cdot, J+1)=0
\end{aligned}
$$

\section{B. Intermediaries}

Competitive financial markets imply zero expected profits on each loan. Since the law of large numbers holds in our model ex-post realized profits also equal zero. This implies that the price of a bond is determined by the default probability of the issuer and the risk free bond 
price. Let $\theta\left(d^{\prime}, z, j\right)$ denote the probability that a household of age $j$ with current productivity shock $z$ and total borrowing $d^{\prime}$ will declare bankruptcy tomorrow. Without garnishment and with full discharge of debt, the zero profit condition is $q^{b}\left(d^{\prime}, z, j\right)=\left(1-\theta\left(d^{\prime}, z, j\right)\right) \bar{q}^{b}$, where $\bar{q}^{b}\left(=\frac{1}{1+r^{s}+\tau}\right)$ is the price of a bond with zero default probability. For positive levels of garnishment, this formula needs to be adjusted for how much lenders can recover from a bankrupt. The bond price under fresh start with wage garnishment is

$$
q^{F S}\left(d^{\prime}, z, j\right)=\left(1-\theta\left(d^{\prime}, z, j\right)\right) \bar{q}^{b}+\theta\left(d^{\prime}, z, j\right) E\left(\frac{\Gamma}{d^{\prime}+\kappa^{\prime}} \mid I=1\right) \bar{q}^{b}
$$

where $E\left(\frac{\Gamma}{d^{\prime}+\kappa^{\prime}} \mid I=1\right)$ is the expected amount that will be garnished. We follow the convention that when a household defaults, the amount garnished is allocated proportionately to the repayment of expense debt and personal bonds.

We need to make further adjustments for the no-fresh start case. For this case, borrowers may be in default for a number of periods and eventually repay their debt. Even if a household stays in default until the end of its life, creditors can garnish a fraction of the income every period, not just in the original bankruptcy period. The bond price under no-fresh start with wage garnishment is

$$
\begin{array}{r}
q^{N F S}\left(d^{\prime}, z, j\right)=\left[\left(1-\theta\left(d^{\prime}, z, j\right)\right)+\theta\left(d^{\prime}, z, j\right) E\left(\frac{\left(\Gamma+q\left(d^{\prime \prime}, z^{\prime}, j+1\right) d^{\prime \prime}\right)}{d^{\prime}+\kappa^{\prime}} \mid I=1\right)\right] \bar{q}^{b} \\
\text { where } d^{\prime \prime}=\frac{\max \left\{d^{\prime}+\kappa^{\prime}-\Gamma, 0\right\}}{\bar{q}}
\end{array}
$$

The first term in parenthesis is the probability that the loan is repaid without default. The second term specifies the expected value of repayment if the household defaults. The key addition from equation (4) is the value of the rolled over household debt $\frac{q\left(d^{\prime \prime}, z^{\prime}, j+1\right) d^{\prime \prime}}{d^{\prime}+\kappa^{\prime}}$. This value is determined by the market value of the rolled over debt.

\section{Equilibrium}

DeFinITION 1. Given a bankruptcy rule $(\bar{y}, g)$, and given the risk-free bond price $q^{s}$, a competitive equilibrium with Fresh Start is a value function $V(\cdot)$, a set of policy functions $h(\cdot)$, $b(\cdot)$, and $I(\cdot)$, a probability of default $\theta\left(b^{\prime}, z, j\right)$, and a pricing function $q^{b}(\cdot)$ such that

1. $V(\cdot)$ satisfies the functional equation 2 , and $h(\cdot), b(\cdot)$, and $I(\cdot)$ are the associated policy functions;

2. Default probabilities are given by $\theta\left(b^{\prime}, z, j\right)=\sum_{K} \sum_{Z} I\left(b^{\prime}, z^{\prime}, k^{\prime}, j+1\right) \pi\left(z^{\prime} \mid z\right) \pi\left(\kappa^{\prime}\right)$;

3. Bond prices $q^{b}(\cdot)$ are determined by the zero profit condition for intermediaries (i.e. equation 4 holds).

Definition 2. A competitive equilibrium with No Fresh Start is defined analogously to above, 
with the modification that $V(\cdot)$ has to satisfy the functional equation (3) and bond prices $q^{b}(\cdot)$ are given by equation (5).

\section{Computation and Existence}

The solution is computed numerically. The algorithm solves the problem backwards by solving for the households' decisions in their last period of life as a function of the state variables. We compute the optimal decisions using a grid for the possible asset holdings.

The proof of existence for the fresh start environment is straightforward. Essentially, all that one has to prove is that, given any $q^{s}$, there exists a schedule of bond prices $q^{b}$ such that intermediaries earn zero profits and the consumers problem is well defined. A formal proof of existence is provided in the appendix.

\section{Calibration}

In this section, we outline our choice of functional forms and our calibration of parameters for the United States and Germany. ${ }^{5}$

Households live for 10 periods. The length of each period is 5 years, and life begins at age 20 . The utility function is

$$
\sum_{j=1}^{10}\left(\prod_{i=1}^{j-1} \beta_{i}\right)\left(\left[\left(c_{j}\right)^{\chi}\left(1-h_{j}\right)^{1-\chi}\right]^{1-\sigma}-1\right) /(1-\sigma)
$$

where $1 / \sigma$ is the intertemporal elasticity of substitution and $\chi$ is consumptions share of the composite commodity.

We parameterize the preference parameters as follows. The $\beta$ are the product of an annual discount factor of 0.96 and the age dependent probabilities of dying reported by the Bureau of the Census. $\chi$ is chosen so that a household with average productivity and labor endowment would choose to allocate 40 percent of its time to working. The benchmark value of $\sigma$ is 2 , which is commonly used in the business cycle literature.

There are two interest rates to calibrate. The savings interest rate is set equal to $4 \%$, which is the average rate of return on capital reported by McGrattan and Prescott (2000) for the U.S. This implies that the risk free return on savings for a five year period is $(1.04)^{5}-1=22 \%$. The second component of the borrowing interest rate is the transaction cost. We set this equal to 5\%. Evans and Schmalnsee (1999) report that, on average, credit card companies operating expenses are $5.3 \%$ of the value of their outstanding balances. ${ }^{6}$ This implies that the risk free cost of borrowing for a five year period is $(1.09)^{5}-1=54 \%$.

\footnotetext{
${ }^{5}$ An Appendix containing a more detailed description of our calibration is available upon request.

${ }^{6}$ This is a conservative estimate, as Davis, Kubler, and Willen (2002) report that the difference between U.S. nominal borrowing and lending rates is on the order of $8 \%-9 \%$.
} 


\section{A. Calibrating the Income Process}

We use the Cross-National Equivalent File of the Panel Study of Income Dynamics (PSID) and the German Socio-Economic Panel (GSOEP) from the Department of Policy Analysis and Management, Cornell University (2002). These data sets provide comparable measures of total hours worked, labor income and the age of the household head. We use the main sample of the PSID and the West German sample of GSOEP.

We allow the productivity shock $z$ to take five possible values. The productivity of household $i$ is the ratio of total labor income to total hours worked by the household. The relative productivities are computed using the years 1991 and 1996. For each year, we compute the mean of each quintile. We restrict attention to households whose head age was between 25-49 so as to avoid our measure of relative productivities being contaminated by life cycle effects. Since we are interested in relative productivities, we normalize the average hourly earnings in each year by the average hourly earnings of the highest income quintile. The values reported in Table I are the average of the values for 1991 and 1996.

\section{Table I}

Relative Productivities (Households Head 25-49 in 1991)

\begin{tabular}{|l|l|l|l|l|l|}
\hline z & 1 & 2 & 3 & 4 & 5 \\
\hline U.S. & 0.21 & 0.29 & 0.38 & 0.52 & 1.0 \\
\hline \hline Germany & 0.28 & 0.41 & 0.50 & 0.61 & 1.0 \\
\hline
\end{tabular}

The transition matrix $\Pi\left(z^{\prime} \mid z\right)$ is computed using the transition between the quintiles in 1991 and 1996. It is computed as the probability of moving between earnings quintiles over a five year period. ${ }^{7}$ The transition matrices are reported in Table II.

To calibrate the life cycle endowment of efficiency units of labor, we use data from 1988-1996. For each year, we compute the mean hourly labor earnings of households with positive hours worked and positive labor income. The age of the household head is used as the age of the household. We report the endowment of efficiency units of labor relative to households whose head is aged 45-49 to 1. The values reported in Table III are the average of the annual results.

Tables I-III illustrate several well know facts. First, the degree of hourly earnings inequality in West Germany is less than that in the United States. Second, the life cycle earnings profile is flatter in West Germany than in the United States. For the U.S., these

\footnotetext{
${ }^{7}$ We would like to have age dependent transition probabilities. We cannot estimate these probabilities using the PSID due to the small sample size (with ten age groups and 5 income groups we have 50 cells implies that we have $25^{*} 9=225$ transition probabilities to estimate).
} 
Table II

Transition Probabilities (Households Head 25-49 in 1991)

\begin{tabular}{|l|l|l|l|l|l|l|l|l|l|l|}
\hline & \multicolumn{5}{|c|}{ United States } & \multicolumn{5}{|c|}{ Germany } \\
\hline $\mathrm{z}$ & 1 & 2 & 3 & 4 & 5 & 1 & 2 & 3 & 4 & 5 \\
\hline 1 & 0.551 & 0.270 & 0.107 & 0.045 & 0.027 & 0.490 & 0.261 & 0.134 & 0.075 & 0.040 \\
\hline 2 & 0.227 & 0.417 & 0.235 & 0.083 & 0.037 & 0.241 & 0.348 & 0.198 & 0.138 & 0.079 \\
\hline 3 & 0.120 & 0.211 & 0.329 & 0.238 & 0.102 & 0.111 & 0.221 & 0.336 & 0.209 & 0.123 \\
\hline 4 & 0.059 & 0.086 & 0.238 & 0.385 & 0.235 & 0.091 & 0.138 & 0.229 & 0.336 & 0.209 \\
\hline 5 & 0.048 & 0.016 & 0.091 & 0.249 & 0.602 & 0.067 & 0.036 & 0.103 & 0.245 & 0.553 \\
\hline
\end{tabular}

Table III

Life Cycle Efficiency Units

\begin{tabular}{|l|l|l|l|l|l|l|l|l|l|l|}
\hline Age & $20-24$ & $25-29$ & $30-34$ & $35-39$ & $40-44$ & $45-49$ & $50-54$ & $55-59$ & $60-64$ & $65-$ \\
\hline U.S. & 0.48 & 0.67 & 0.82 & 0.93 & 1.02 & 1.00 & 1.03 & 1.06 & 1.00 & 0.91 \\
\hline Germany & 0.76 & 0.79 & 0.84 & 0.90 & 0.98 & 1.00 & 0.98 & 0.91 & 0.95 & 0.79 \\
\hline
\end{tabular}

values are roughly consistent with those of Hansen (1993). One difference is that the life cycle profile computed here does not decline as much as expected for older households. Our conjecture is that this is due to the fact that most older households do not work in the sample, so that there is a selection bias. ${ }^{8}$

\section{B. Expense Uncertainty}

To calibrate the expense shock, we look at data on expenses that are both unexpected and beyond the direct control of a household. We consider three different sources of shocks: medical bills, divorces and unplanned pregnancies. All three of these shocks are frequently cited by bankrupts as the proximate cause of their bankruptcy.

Expense shocks take one of three possible values: $\kappa \in\left\{\kappa_{1}, \kappa_{2}, 0\right\}$. We also need the associated probabilities: $\pi_{1}, \pi_{2}$, and $\left(1-\pi_{1}-\pi_{2}\right)$. Our calibration strategy is to collapse the data on the three different shocks into three similar mass points, and then to sum the probabilities of the three shocks.

\section{B.1. Data on medical expenditures}

We utilize data from the Medical Expenditure Panel Survey (MEPS) and the US Health Care Financing Administration (HCFA) to calibrate the medical expense shock. MEPS provides detailed data on medical expenses in 1996 and 1997 for a random sample

\footnotetext{
${ }^{8}$ It is unclear how large this bias is. Neumark and Johnson (1996) look at data from the National Longitudinal Survey of Older Men, and find that wage declines for men only set in for workers in their 60's.
} 
of 19,859 persons (7,435 households). For each person in the sample, total medical charges, expenditures, out of pockets payments and monthly insurance status are reported.

To find total medical bills received by household, we need to make two adjustments to the out of pocket spending figures reported in MEPS. First, out of pocket spending reported in MEPS is too low compared to aggregate data. Average out of pocket spending in 1996 was $\$ 1,718$ in $1996,{ }^{9}$ whereas the average for the MEPS data set is only $\$ 867.85$. Assuming that everyone underreports the same fraction of personal health care expenditures, we multiply the MEPS numbers by a constant factor (1.98 and 2.09 for 1996 and 1997, respectively) to get aggregate out of pocket expenditures.

The second problem with MEPS is that the reported out of pocket expenditures do not include unpaid debts and thus underestimate the medical bills incurred by households. ${ }^{10}$ This is of particular importance as we are interested in the magnitude of debt that may be discharged via bankruptcy. We impute the quantity of unpaid medical bills as follows. We first compute an estimate of bad debt. The American Hospital Association (1996) reports that U.S. hospital bad debt in 1996 was $\$ 16.4$ billion. This is approximately 4.6 percent of total spending on hospitals in 1996. Assuming that bad debt for the entire medical sector is also equal to 4.6 percent, we impute $\$ 42$ billion of bad debt for 1996 and $\$ 44$ billion for 1997. ${ }^{11}$ To generate household bad debt, we allocate the bad debt to individuals who were not insured for at least one month in a given year.

Formally, we compute the medical shock $s_{i}^{j}$ of individual $i$ in year $j$ as the sum of out-of-pocket expenses (oop) plus a fraction $b^{j}$ of the difference between the total charges (char) less total expenditures $(\exp ) .{ }^{12}$

$$
s_{i}^{j}=a^{j} o o p_{i}^{j}+b^{j} I_{i}^{j}\left[\operatorname{char}_{i}^{j}-\exp _{i}^{j}\right]
$$

where $I_{i}^{j}=0$ if $i$ was insured all of year $j$, and 1 otherwise. The parameters $b^{j}$ are chosen so that the implied bad debt is $\$ 42$ and $\$ 44$ respectively. This gives $b^{96}=0.69$ and $b^{97}=0.44{ }^{13}$ To compute the shock of a household $k$ in year $j, s_{k}^{j}$, we add up $s_{i}^{j}$ for all household members.

Since a period in the model is 5 years, we are interested in medical expenses over a five year horizon. The data from 1996 and 1997 shows some persistence over time. We account

\footnotetext{
${ }^{9}$ Total out of pocket spending in 1996 was $\$ 171.2$ billion. The number of households in 1996 was 99,627,000, which gives an average of $\$ 1,718$ per household.

${ }^{10}$ Total medical charges have the opposite problem, as it includes charity care and does not account for discounts routinely given by hospitals on medical bills.

${ }^{11}$ Total personal health care expenditures were $\$ 924$ and $\$ 969$ billion for 1996 and 1997 respectively (HCFA 1998).

${ }^{12}$ For some individuals medical spending reported is higher than charges. For these cases, we set the difference equal to 0 .

${ }^{13}$ The number for 1997 is much lower because the difference in charges and expenditures reported in MEPS increased about 50\% from 1996 to 1997.
} 
for this persistence as follows. We regress $s_{k}^{96}$ on $s_{k}^{97}$ and find a persistence parameter of 0.23. We then estimate the shocks for the following three years using the regression results: $s_{k}^{j}=\$ 1,745+0.23 s_{k}^{j-1}+e_{k}^{j}$, where the errors $e_{k}$ are drawn from the empirical distribution of errors. ${ }^{14}$ The final 5-year household medical shock is the sum of the shocks for 1996 and 1997 and the three constructed annual shocks. These shocks are large as can be seen from Figure 1. On average, a household spends about $\$ 11,200$ on medical bills over a five year period. A small fraction of households have immense medical bills. The highest amount is $\$ 335,500$, which is roughly eight times average annual income.

Household medical expenditures are lower in Germany compared to the U.S. because of compulsory health insurance. Total medical spending by private households in 1996 was DM 42 billion (Federal Statistical Office Germany, 1998). This gives average annual out of pocket spending for a German household of DM 1127. Since there is no analogue of MEPS in Germany we assume that the distribution across households is the same as out of pocket spending in the U.S. The U.S. distributions for 1996 and 1997 are each scaled so that the mean is exactly DM 1127. No adjustment for bad debt is made. We then estimate persistence and construct shocks for three more years in the same way as for the US. The medical shock histogram for Germany is also reported in Figure 1. Medical shocks are much lower in Germany. The average 5-year shock is only DM 5,635 compared to $\$ 11,200$ in the U.S.

\section{B.2. Data on Divorces and Children}

Panel data on divorce and child costs is unavailable. We therefore cannot look at the entire distribution of shocks as we did for the medical case. Instead, aggregate numbers are used to estimate one probability and one magnitude for the child and the divorce shock.

The probability of the divorce shock is easy to compute. In 1996, there were 99,627,000 households and 1,159,000 divorces (U.S. Census Bureau (2000)) in the US. In Germany there were $37,381,000$ households and 176,203 divorces . The annual divorce probability is $1.15 \%$ in the US and $0.4 \%$ in Germany. We assume that a household can have at most one divorce in a five year period. This implies that the probability of a divorce shock in the U.S. and Germany is $5.6 \%$ and $1.98 \%$, respectively.

We consider two different costs of divorce, legal fees and the loss of economies of scale. Legal fees associated with a divorce can vary from less than a thousand dollars to hundreds of thousands. We choose a figure of $\$ 5,000$ for the US, which is if anything a lower bound on the average legal costs of divorce. This corresponds to $12 \%$ of mean annual wage income. Using the same fraction for Germany, this gives DM 6,840. The second cost we consider is the loss

\footnotetext{
${ }^{14}$ In some cases this method will give negative expense shocks. We set these shocks equal to 0 , and then scale down all positive shocks such that the size of the aggregate shock is kept constant.
} 
of economies of scale associated with the breakup of a household. On average, one child is involved in a divorce. Thus, the average divorce involves the division of a 3-person household into a 1-person and a 2-person household. We use equivalence scales (ES) reported in the literature to compute the decrease in effective income. ${ }^{15}$ Using this equivalence scale, for the average divorce, effective income drops by $28 \%$. Multiplying this by an average household income of $\$ 43,000$, this implies an annual decline of $\$ 12,040$. The average divorcee remains single for about 4 years. This yields a value for the total divorce shock of $\$ 53,160$ for the US. The German average income is DM 57,000, which gives a total divorce shock of DM 70,680.

The third shock is the cost of an unwanted child. In the U.S., $30 \%$ of all births are unintended (U.S. Census Bureau (2000)). However, only 9.1\% are unwanted. In 1996, there were 3,891,000 births. Multiplying this by the fraction of unwanted children yields 354,081 unwanted births. Dividing this by 99,627,000 households implies an annual child shock probability of 0.00355 . We assume that this shock is independent over time, which implies that the probability of having at least 1 unwanted child in 5 years is 0.0176 . The total number of births in Germany in 1996 was 796,013, and 12\% of these resulted from unplanned pregnancies. ${ }^{16}$ Assuming that the probability of having an unwanted child is the same as in the U.S., the probability of having an unplanned and unwanted child in Germany is $0.085 \%$.

The U.S. Department of Agriculture (1996 annual report) reports a range of estimates for the average annual expenditures for a child less than 2 years old. We use their intermediate estimate of $\$ 8,000$ as the annual child cost. Assuming that these costs are incurred for 5 years, we have a shock of size $\$ 40,000$ for the U.S. This is $93 \%$ of annual mean income. Similarly, we estimate the magnitude of the German child shock to be DM 53,023.

\section{B.3. Calibrating the Expense Shock}

We need to collapse the distributions of the three shocks into 4 numbers $\left(\kappa_{1}, \kappa_{2}, \pi_{1}, \pi_{2}\right)$ for each country. Since the divorce and child shock amounts are of similar size, we combine them into the low expense shock by computing the weighted average. For the U.S. this gives $\kappa_{2}=\$ 50,013$ and for Germany DM 67,590. Medical shocks for the U.S. can be extremely high, up to 9 times annual income. We therefore pick the high shock $\kappa_{1}=\$ 210,000$, which corresponds to five times annual income. Taking the households with the 19 highest shocks gives exactly a mean shock of this amount, which corresponds to a probability of $\pi_{1}=0.00256$ (19 out of 7435 households). Finally, we pick the next group of households in the distribution such that the average shock amount equals $\kappa_{2}$, this gives a probability of 0.04 . Let $\pi_{2}=0.1138$ be the probability of having at least one of the three lower shocks.

\footnotetext{
${ }^{15}$ We use the average of a number of studies reported in Fernandez-Villaverde and Krueger (2000). The equivalent scale for a 3 person household is 1.77

${ }^{16}$ As reported in Population Action International, 2001
} 
For Germany, there is no shock of the size comparable to $\kappa_{1}$ in the U.S. We therefore collapse all three shocks into a single shock. Using the same methodology as for the U.S., we obtain $\kappa_{2}=\operatorname{DM} 67,590$ and $\pi_{2}=0.02534$.

Table IV summarizes the three expense shocks. The actual values we use are the above values relative to average household disposable income.

Table IV

Expense Shocks

\begin{tabular}{|l|l|l|l|l|l|}
\hline & magnitude & medical & divorce & child & combined \\
\hline \multirow{4}{*}{ U.S. } & $\$ 40,000$ & - & - & 0.0176 & \multirow{3}{*}{$0.1138\left(\pi_{2}\right)$} \\
\cline { 2 - 6 } & $\$ 50,013\left(\kappa_{2}\right)$ & 0.0402 & - & - & \multirow{3}{*}{$0.00256\left(\pi_{1}\right)$} \\
\cline { 2 - 5 } & $\$ 53,160$ & - & 0.056 & - & \multirow{2}{*}{$0.0253\left(\pi_{2}\right)$} \\
\cline { 2 - 5 } & $\$ 210,000\left(\kappa_{1}\right)$ & 0.00256 & - & - & \\
\hline \hline \multirow{3}{*}{ Germany } & DM53,023 & - & - & 0.0042 & \\
\cline { 2 - 5 } & DM67,590 $\left(\kappa_{2}\right)$ & 0.00134 & - & - & \\
\cline { 2 - 5 } & DM70,680 & - & 0.0198 & - & \\
\hline
\end{tabular}

\section{Bankruptcy Rules}

The parameters associated with bankruptcy, $\lambda, g, \bar{y}$ and $\bar{r}$, also need to be specified. We set $\lambda=0.04$. An important issue in calibrating garnishment levels is that households typically have to wait some time before defaulting. Bankruptcy codes contain general provisions that borrowers must act in "good faith," so that borrowing and immediately filing for bankruptcy runs some risk of being denied. The parameter $g$ is intended to capture this fact by requiring that agents must repay at least some fraction of their debt. Our benchmark value of $g$ is 0.35. We set the exemption level, $\bar{y}$, equal to $15 \%$ of mean earnings. The rollover interest rate is set to the risk free borrowing interest rate plus $2 \%$. We discuss the sensitivity of our results to these parameters below. The benchmark parameters are summarized in Table V.

Table V

Benchmark Bankruptcy Parameters

\begin{tabular}{|r|r|r|r|}
\hline$\lambda$ & $g$ & $\bar{y}$ & $\bar{r}$ \\
\hline 0.04 & 0.35 & $15 \%$ avg. earnings & 0.69 \\
\hline
\end{tabular}

\section{Results}

This section is organized as follows. The first part describes the benchmark case in detail, compares it to the data, and analyzes the basic forces at work in our model. The second part 
consists of several policy experiments that show how the welfare conclusions depend on the garnishment technology, the interest rate and the expense shocks.

For each experiment, we report four key statistics: the average borrowing interest rate, debt relative to household earnings, the fraction of households declaring bankruptcy, and the percent increase in lifetime consumption required to compensate for the difference in welfare between the two policy regimes. The average borrowing interest rate is the debt-weighted average interest rate. Our measure of welfare is the ex ante expected utility of an agent about to be born into our economy. All numbers are reported on an annual basis. ${ }^{17}$

Before turning to the results, we review the basic trade-off between Fresh Start (FS) and No Fresh Start (NFS). Borrowing as a means to smooth intertemporally is desired due to the life-cycle earnings profile, while the lack of insurance markets creates a role for bankruptcy as a way to smooth across states. Each bankruptcy regime facilitates one type of smoothing while limiting the other. Under FS, it is relatively easy to discharge debt via bankruptcy, facilitating smoothing across states. However, this makes intertemporal smoothing difficult as it both constrains borrowing and increases borrowing interest rates. Under NFS, bankruptcy merely allows a household to spread the effects of a bad shock across time, as debt is not discharged. Hence, bankruptcy under NFS is not as helpful in terms of smoothing consumption across states. On the other hand, the lower default rate and increased garnishment lowers the interest rate and relaxes households' borrowing constraints, which makes it easier and less costly to smooth across time. The welfare comparison between FS and NFS therefore depends on which type of smoothing is more important. This depends on several factors, including the magnitude of the expense shocks, the steepness of the life cycle earnings profile, and the risk-free interest rate.

\section{A. Benchmark Experiment}

The first row of Table VI summarizes the results for the benchmark parameters. The benchmark model implies a debt over earnings ratio of $8.3 \%$. In 1996, unsecured consumer debt in the U.S. was 8.8 percent of personal disposable income. ${ }^{18}$ The lower debt/earnings ratio predicted by the model is reasonable, as we abstract from several important motivations for borrowing, such as the purchase of durable goods. Moreover, 8.8\% may overestimate unsecured consumer debt, since it includes borrowing by small business owners to finance business operations.

The benchmark parameters generate an annual default rate of $0.53 \%$. There were 673,123 non-business Chapter 7 bankruptcy filings in 1996, which corresponds to $0.68 \%$ of all households. This number is an overestimate of the number of consumer bankruptcies, as

\footnotetext{
${ }^{17}$ Since each period in the model corresponds to five years, annual interest rates are $\left(1 / q^{b}\right)^{1 / 5}-1$, and the stock of debt relative to the flow of earnings is multiplied by 5 .

${ }^{18}$ We use revolving credit as reported by the Federal Reserve as our measure of unsecured debt.
} 
it includes filings caused by the failure of unincorporated small businesses. The benchmark model is able to account for over three-quarters of the observed bankruptcies. As we discuss below, the default rate is sensitive to the amount of uncertainty in the economy and the bankruptcy rule parameters.

The third column of Table VI reports the average borrowing interest rate in the economy. The Federal Reserve reports two interest rates for unsecured loans. The average (nominal) interest rate for two year personal loans in 1996 was $13.5 \%$ while the average interest rate on credit cards assessed interest was $15.5 \%$. The average rate of CPI inflation in the U.S. from 1995-2000 was 2.6\%. This implies an average real cost of unsecured consumer borrowing of between $11 \%$ and $12.9 \%$. The benchmark parameters generates an average borrowing interest rate in this range of $11.7 \%$.

Table VI

Results

\begin{tabular}{|c|c|c|c|c|c|c|c|}
\hline & Results & Rule & Debt/Earnings & Defaults & Avg. $r^{b}$ & better rule & Cons. Equiv. \\
\hline 1 & Benchmark & FS & $8.33 \%$ & $0.53 \%$ & $11.66 \%$ & \multirow{2}{*}{ FS } & \multirow{2}{*}{$0.39 \%$} \\
\hline & U.S. & NFS & $17.04 \%$ & $0.10 \%$ & $9.64 \%$ & & \\
\hline & U.S. Data & $\overline{F S}$ & $8.8 \%$ & $0.68 \%$ & $12.0 \%$ & - & - \\
\hline \multirow[t]{2}{*}{2} & No expense & FS & $11.04 \%$ & $0.00 \%$ & $9.01 \%$ & \multirow{2}{*}{ NFS } & \multirow{2}{*}{$0.68 \%$} \\
\hline & U.S. & NFS & $31.69 \%$ & $0.22 \%$ & $13.01 \%$ & & \\
\hline \multirow[t]{2}{*}{3} & $\bar{c} r^{s} \downarrow 1 \%$ & FS & $12.02 \%$ & $0.60 \%$ & $10.01 \%$ & \multirow{2}{*}{$\mathrm{FS}$} & \multirow{2}{*}{$0.03 \%$} \\
\hline & U.S. & NFS & $25.93 \%$ & $0.17 \%$ & $9.97 \%$ & & \\
\hline \multirow[t]{2}{*}{4} & 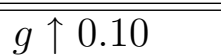 & $\overline{\mathrm{FS}}$ & $10.15 \%$ & $0.35 \%$ & $10.87 \%$ & \multirow{2}{*}{ NFS } & \multirow{2}{*}{$0.00 \%$} \\
\hline & U.S. & NFS & $19.35 \%$ & $0.04 \%$ & $9.23 \%$ & & \\
\hline \multirow[t]{2}{*}{5} & Benchmark & FS & $6.11 \%$ & $0.06 \%$ & $9.44 \%$ & \multirow{2}{*}{ NFS } & \multirow{2}{*}{$0.04 \%$} \\
\hline & Germany & NFS & $9.36 \%$ & $0.02 \%$ & $9.20 \%$ & & \\
\hline
\end{tabular}

In the benchmark economy, welfare is higher under FS than under NFS. This implies that the benefits from increased smoothing across states outweigh the distortion of intertemporal credit markets. As expected, defaults and interest rates are higher under FS than under NFS. This low default rate, together with the fact that creditors can garnish wages of bankrupts for more than one period, means that in effect almost all debt is recovered, leading to an average interest rate that is only slightly higher than the risk-free rate. As a result, the level of borrowing under NFS is almost twice that of FS.

We find that interest rates are highly sensitive to the current productivity shock of the borrower as well as to the amount borrowed. Figure 2 shows bond prices for households of age 1 under FS, while Figure 3 is the corresponding graph for NFS. Each line in the graph 
corresponds to a specific productivity shock. The graph shows that higher income borrowers receive lower interest rates (higher bond prices) than low income borrowers. This is due to the lower default probability of high income borrowers. For all borrowers, the bond price converges to zero as the face value of the loan increases.

A key aspect of models with bankruptcy is the endogenous borrowing constraints. These constraints for plotted for age 1 household under FS and NFS, respectively, in Figures 4 and 5. Each line in the graph corresponds to a specific productivity shock. There figures illustrate two key points. First, that the borrowing constraints for young households are significant. Second, that the borrowing constraints under FS are significantly tighter than those under NFS.

A key argument that has been advanced in favor of FS is the effect that bankruptcy rules have on labor supply decisions. According to this argument, the life-long liability of debt may cause debtors to "give up" and not work at all for the rest of their lives, while the discharge of debt allows the debtor to start afresh, and hence provides the right work incentives. While we do not find evidence of this, we do find that bankruptcy rules impact life-cycle labour supply decisions. Labour supply by age 1 households under FS is slightly higher than under NFS, as these households face tighter intertemporal borrowing constraints. Conversely, middle aged household work slightly harder on average under NFS. Interestingly, most households which received an expense shock under NFS worked harder than their counterpart under FS. This behaviour is driven by the fact that households receiving an expense shock under NFS experience a larger reduction in wealth than their counterpart under FS. Additionally, since bankruptcy is costly, households have an additional incentive to work hard so as to escape bankruptcy. This leads us to conclude that, for our garnishment technology, NFS actually provides superior work incentives than FS.

\section{A.1. Profile of Bankrupts}

The model offers a rich set of predictions on the characteristics of bankrupts. These predictions are of interest as comparing them to the data (discussed in Section 2) provides a check on the performance of our model.

The overall impression of bankrupts is similar to the picture painted by Sullivan, Warren, and Westbrook (2000). Table VII reports the demographic profile of bankrupts for the benchmark parameters and for the U.S. The U.S. values are from Sullivan, Warren, and Westbrook (2000), and are based on bankruptcy filings in four districts in 1991. To facilitate comparison, we have normalized the bankruptcy filing rate for each age group by the average number of bankruptcy filings for all households. Table VII indicates that the model predicts a steeper profile of defaults than that observed in the data. The steeper age profile in the model is driven by the fact that virtually all borrowing is by young households seeking to smooth consumption intertemporally. This causes a sharper spike in defaults for young households 
in the model than in the data.

\section{Table VII}

Age Profile of Bankrupts:

FS Benchmark Parameter Values and U.S. Data

\begin{tabular}{|l|c|c|c|c|c|c|c|c|c|}
\hline Age & $25-29$ & $30-34$ & $35-39$ & $40-44$ & $45-49$ & $50-54$ & $55-59$ & $60-64$ & avg. \\
\hline \hline Model & 2.64 & 1.95 & 1.31 & 1.06 & 0.78 & 0.84 & 0.74 & 0.67 & 1.00 \\
\hline Data & 1.25 & 1.53 & 1.44 & 1.57 & 1.45 & 0.84 & 0.91 & 0.17 & 1.00 \\
\hline
\end{tabular}

We find that most bankrupts are in the lower income group of their age cohort. There are also a small number of upper income households who default. The ratio of mean income of bankrupts to average household income is 0.55 . This is similar to the values reported in Sullivan, Warren, and Westbrook (2000). Most households who receive an expense shock do not declare bankruptcy: Only one in four households hit by the small expense shock and roughly two in three households hit by the large expense shock declared bankruptcy under FS. This suggests that our expense shocks are not so large that they "force" households into bankruptcy as most households choose to pay the expense shock rather than default.

\section{B. The Role of Expense Shocks}

We undertook several experiments to better understand the role of expense uncertainty in evaluating bankruptcy rules. Experiment 2 in Table VI reports the result of one such experiment, where we set both expense shocks equal to zero while holding the remaining U.S. benchmark parameters fixed. The debt to earnings ratio increases under both bankruptcy regimes compared to the benchmark, although by much more in NFS than in FS. This is due to two factors. First, the elimination of expense shocks increases household wealth. However, the increase in expected household wealth under FS is less than the corresponding increase in wealth under NFS. Second, the elimination in expense uncertainty reduces households precautionary savings motives. Interestingly, both the average borrowing interest rate and the number of bankruptcies are higher under NFS than under FS. We also find that NFS yields higher ex ante utility than FS. This result is not surprising, as the elimination of expense uncertainty reduces the value of insurance against "bad luck" that FS provides.

This result is consistent with Athreya (2002), who in a model which abstracts from expense uncertainty finds that eliminating bankruptcy in the U.S. would increase welfare. Our experiments show, for reasonable parameter values, that introducing expense uncertainty changes the welfare evaluations of FS versus NFS bankruptcy codes. This finding lends support to the views advanced by sociologists and lawyers such as Sullivan, Warren, and Westbrook (2000) that bankruptcy plays an important role in providing a safety net against bad luck for Americans. We believe that this finding indicates that incorporating expense 
uncertainty is crucial in any analysis of alternative bankruptcy rules.

\section{Decrease in Interest Rate}

We also explored the sensitivity of our findings to the risk free savings rate. Experiment 3 report the results of decreasing the risk free savings rate to an annual rate of $3 \%$. The lower risk free rate leads to higher levels of debt, defaults and a lower borrowing interest rate. The lower interest rate also leads to a lower welfare gap between FS and NFS. This is due to the interplay between the benefits from smoothing across time and states. A lower interest rate increases the benefits to young households of borrowing to smooth consumption intertemporally. This increases the costs of the stricter debt constraints of FS, and hence reduces the value of FS relative to NFS.

\section{Change in Garnishment}

The fourth experiment is an increase in the garnishment rate from $35 \%$ to $45 \%$. This increases the punishment for declaring bankruptcy and increases the amount that can be recovered from debtors. Since bankruptcy is now more costly, default rates and the average borrowing interest rate decline while the debt/earnings ratio increase under both FS and NFS. The intuition for this is that the increased ability of lenders to collect on debts leads to the relaxation of borrowing constraints. Since the bankruptcy rule has a relatively low rollover rate, the gain in intertemporal smoothing (due to the relaxation of borrowing constraints) dominates the insurance aspect. This leads to welfare being (slightly) higher under NFS than FS.

\section{E. German Benchmark}

The final experiment reported in Table VI uses the benchmark parameter values for Germany. Compared to the experiments using U.S. parameters, average borrowing interest rates, debt/earnings and defaults are lower. The lower debt/earnings ratio is driven by the flatter life cycle earnings profile in Germany than in the U.S. The interest rate predicted by the model is in line with German data. The average real "Dispositionskredit", which is the average interest rate on overdraft protection credit for chequeing accounts (which play an analogous role to credit cards in the U.S.), in 2000 was approximately $10 \%$, which is slightly higher than the rate predicted by the model. Unfortunately, we have not been able to locate comparable statistics for unsecured credit to those reported for the U.S. Total household liabilities as a fraction of disposable income were higher in Germany than in the U.S. in 1998 (110.9 percent in Germany compared to 99 percent in the U.S.(OECD 2002)). The one measure we have of bankruptcies is the stock of wage earners whose wages are currently being garnished. In 1999, $1.85 \%$ of German wage earners were subject to wage garnishment (Korczak (2001)). The number predicted by the model under NFS is slightly higher at 2.20 
$\%$.

In contrast with the U.S. benchmark experiment, the NFS system yields higher ex ante utility than FS. This result was not preordained. While the lower level of uncertainty in Germany reduces the value of insurance against shocks, the flatter life productivity profile reduces the costs of distorting intertemporal credit markets. We view this reversal in the welfare rankings of FS and NFS as suggesting that the variation in consumer bankruptcy law across countries may be linked to variations in the amount of uncertainty households face. To further explore this conjecture, we repeated the German experiment with expense shocks set to the U.S. shocks to the U.S. level. In this case, we find that welfare is higher under the FS system. This implies (not surprisingly) that welfare comparisons of bankruptcy rules are sensitive to the degree of risk faced by households in different countries.

\section{Conclusion}

In this paper, we develop a formal model of consumer bankruptcy with a competitive lending market, and use it to quantitatively analyze different consumer bankruptcy rules. Our model generates interest rates that differ across types of consumers and also depend on the consumer's total debt. For reasonable parameter values, it is also able to closely match the level of unsecured consumer debt, bankruptcy filings rates and average interest rates.

The main message of this paper is that U.S. households face substantial uncertainty from shocks other than variations in income. As we document in section B, these shocks are much larger for American than German households. Moreover, incorporating what we call expense shocks changes the welfare comparison of bankruptcy rules for reasonable parameter values. This result has important implications for the debate in the U.S. with regards to tightening the existing bankruptcy legislation. Athreya (2002) and Li (2001) abstract from expense uncertainty and differential interest rates, and conclude that tightening U.S. bankruptcy laws would lead to welfare gains. Our results suggest incorporating these two features can lead to different implications for policy analysis. In future work, we hope to refine our model so that we can conduct more detailed analysis of proposed changes to U.S. bankruptcy legislation.

Finally, it is worthwhile to speculate on the extent to which we should take this model seriously. One assumption that deserves some discussion is the observability of income and total debt and whether banks indeed condition loan contracts on income and debt level. Many creditors employ scoring models as part of their evaluation of consumer debt (see Engen (2001)). These scoring models employ data on a household's current debt level, the number of recent applications for credit from other sources and the amount that the household wishes to loan, when deciding upon the interest rate to charge and whether to make the loan. In addition, applicants are required to provide information about their employment and income. 
While some applicants provide inaccurate information, it is worth noting that bankruptcy law does not allow for the discharge of loans obtained via fraudulent means.

One aspect of bankruptcy that we abstract from is durable assets which may be seized by creditors. A study cited by the National Bankruptcy Review Commission (1997, p. 136) reported that 95 percent of Chapter 7 cases yielded no assets which could be liquidated to repay creditors. Moreover, most of the 5 percent of cases that did have assets which could be liquidated were business cases. This suggests that abstracting from the seizure of durable goods is reasonable given that our focus in this paper is on Chapter 7 bankruptcy. However, given the important role that durables good play both as a motive for borrowing and as a means of collateralizing debt, in future work we plan to extend the model to incorporate durable goods. 


\section{References}

AiYagari, S. R. (1994): "Uninsured Idiosyncratic Risk and Aggregate Saving," Quarterly Journal of Economics, 109, 659-84.

Alexopoulos, M., And I. Domowitz (1998): "Personal Liabilities and Bankruptcy Reform: An International Perspective," International Finance Journal, 1, 127-159.

American Hospial Association (1996): "AHA Annual Survey," Chicago: Health Forum, an affiliate of the American Hospital Association.

Athreya, K. (2000): "Bankruptcy Exemptions, Consumption, and Interest Rates in an Incomplete Insurance Economy," Federal Reserve Bank of Richmond, mimeo.

(2002): "Welfare Implications of the Bankruptcy Reform Act of 1999," Journal of Monetary Economics, 49, 1567-1595.

Berge, C. (1963): Topological Spaces. Oliver and Boyd.

Chatterjee, S., D. Corbae, M. Nakajima, and J.-V. Rios-Rull (2001): "A Quantitative Theory of Unsecured Consumer Credit with Risk of Default," University of Pennsylvania, mimeo.

Davis, S. J., F. Kubler, and P. Willen (2002): "Borrowing Costs and the Demand for Equity Over the Life Cycle," mimeo.

Department of Policy Analysis and Management, Cornell University (2002): "GSOEP 1984-2000 and the Cross-National Equivalent File 1980-2000 PS-GSOEP-PSIDSLID," CD-ROM.

Domowitz, I., and R. L. SARTAin (1999): "Determinants of the Consumer Bankruptcy Decision," The Journal of Finance, 54(1), 403-420.

Dubey, P., J. Geanakoplos, and M. Shubik (2000): "Default in a General Equilibrium Model with Incomplete Markets," mimeo.

Engen, J. (2001): "Blind Faith," Banking Strategies.

Evans, D., And R. Schmalnsee (1999): Paying with Plastic: The Digital Revolution in Buying and Borrowing. MIT Press, Cambridge, Massachusetts.

Federal Statistical Office Germany (1998): Statistical Yearbook 1998: Federal Republic Germany. Metzler Poeschel, Berlin, Germany. 
Fernandez-Villaverde, J., and D. Krueger (2000): "Consumption and Saving over the Life Cycle: How Important are Consumer Durables?," mimeo.

Hansen, G. D. (1993): "The Cyclical and Secular Hehaviour of the Labor Input: Comparing Efficiency Units and Hours Worked," Journal of Applied Econometrics, 8, 71-80.

Jacoby, M., T. A. Sullivan, And E. Warren (2000): "Medical Problems and Bankruptcy Filings," Norton Bankruptcy Law Advisor, (5).

Kehoe, T., And D. Levine (1993): "Debt-Constrained Asset Markets," The Review of Economic Studies, 60(4), 865-888.

Kocherlakota, N. R. (1996): "Implications of Efficient Risk Sharing without Commitment," The Review of Economic Studies, 63(4), 595-609.

KorczaK, D. (2001): Ueberschuldung in Deutschland zwischen 1988 und 1999Kohlhammer, Stuttgart, Berlin, Koeln.

LI, W. (2001): "To Forgive or Not to Forgive: An Analysis of U.S. Consumer Bankruptcy Choices," Federal Reserve Bank of Richmond Economic Quarterly, 87(2), 1-22.

Li, W., And P.-D. SARTE (2002): "Chapter 7 or Chapter 13: An Analysis of U.S. Consumer Bankruptcy Choice," mimeo, Federal Reserve Bank of Richmond.

McGrattan, E. R., And E. C. Prescott (2000): "Is the Stock Market Overvalued?," Federal Reserve Bank of Minneapolis Quarterly Review, 24(4), 20-40.

Medical Expenditure Panel Survey (1996): "Full Year Consolidated Data File HC012," Agency for Healthcare Research and Quality, Rockville, MD.

(1997): "Full Year Consolidated Data File HC-020," Agency for Healthcare Research and Quality, Rockville, MD.

National Bankruptcy Review Commission (1997): "Bankruptcy: The Next Twenty Years. Final Report of the Bankruptcy Review Commission," Discussion paper, http://www.nbrc.gov/reportcont.html.

Neumark, D., And R. W. Johnson (1996): "Wage Declines among Older Men," Review of Economics and Statistics, 78(4), 740-748.

Niemi-Kiesilainen, J. (1997): "Changing Directions in Consumer Bankruptcy Law and Practice in Europe and USA," Journal of Consumer Policy, 20, 133-142. 
Population Action International (2001): "The PAI Report Card 2001 - A World of Difference: Sexual and Reproductive Health \& Risks," Washington D.C., USA.

RATH, L. (1996): "Ueberschuldung und Schuldnerberatung in Deutschland unter besonderer Beruecksichtigung der neuen Insolvenzordnung (InsO)," Diplomarbeit im Fachbereich Sozialwesen,", Master's thesis, Fachhochschule Fulda.

Repetto, A. (1998): "Personal Bankruptcies and Individual Wealth Accumulation," mimeo.

Sullivan, T., And E. Warren (1999): "The Changing Demographics of Bankruptcy," Norton Bankruptcy Law Adviser.

Sullivan, T. A., E. Warren, and J. L. Westbrook (2000): The Fragile Middle Class. Yale University Press, New Haven and London.

U.S. Census Bureau (1999): Statistical Abstract of the United States, Washington, D.C. (2000): Statistical Abstract of the United States, Washington, D.C.

US Health Care Financing Administration (1998): Health Care Financing Review, Washington, D.C.

Zame, W. R. (1993): "Efficiency and the Role of Default When Security Markets are Incomplete," The American Economic Review, 83(5), 1142-1164. 


\section{Appendix}

\section{Existence Proof for Fresh Start Regime.}

The existence proof for this economy involves showing that bond prices are well-defined and that the household's problem has a solution.

We introduce the following notation: Let $V_{j}^{R}(d ; z, \kappa)$ be the value of repaying the debt for a household of age $j$ as a function of debt $d$, given current productivity and expense shocks $(z, \kappa)$. Similarly, let $V_{j}^{B}(z)$ be the value of declaring bankruptcy, which does not depend on the debt level under fresh start regime. We will say that function $f(d)$ has an irrelevant tail (IT) if $\exists d_{0}, D$ such that $f(d) \leqslant f\left(d_{0}\right) \quad \forall d \geqslant D$. Finally, we will say that two function $f(d)$ and $g(d)$ satisfy the single crossing property (SCP) if $\exists D$ such that $f(d) \geqslant g(d) \quad \forall d \leqslant D$ and $f(d)<g(d) \quad \forall d>D$.

The proof is by backward induction and involves the following steps.

1. Show that $V_{J}^{R}(d ; z, \kappa)$ and $V_{J}^{B}(z)$ are well-defined, u.s.c. and decreasing in $d$ and satisfy the SCP.

2. Show that if $V_{j+1}^{R}(d ; z, \kappa)$ and $V_{j+1}^{B}(z)$ satisfy the SCP, then $q_{j}\left(d^{\prime}, z\right)$ is u.s.c. and decreasing in $d$, and that $q_{j}\left(d^{\prime}, z\right) d^{\prime}$ has an IT.

3. Show that if $q_{j}\left(d^{\prime}, z\right)$ is u.s.c. and decreasing, $q_{j}\left(d^{\prime}, z\right) d^{\prime}$ has an IT, $V_{j+1}^{R}(d ; z, \kappa)$ and $V_{j+1}^{B}(z)$ are u.s.c. and decreasing in $d$, then $V_{j}^{R}(d ; z, \kappa)$ and $V_{j}^{B}(z)$ are well-defined, u.s.c. and decreasing in $d$ and satisfy the SCP.

4. It then follows that at any age $j$ the prices are well-defined and household's problem has a solution.

\section{A1. Last Generation.}

The value of repaying:

$$
\begin{aligned}
V_{J}^{R}(d ; z, \kappa) & =\max _{h} u\left(\bar{e}_{J} z h-d-\kappa, 1-h\right) \\
\text { s.t. } h & \in\left[\max \left\{0, \frac{d+\kappa}{\bar{e}_{J} z}\right\}, 1\right]
\end{aligned}
$$

for $d \leqslant \bar{e}_{J} z-\kappa$ (when the constraint set is non-empty), and $V_{J}^{R}(d ; z, \kappa)=-\infty$ for $d>\bar{e}_{J} z-\kappa$.

The value of non-repayment:

$$
\begin{aligned}
V_{J}^{B}(z) & =\max _{h} u\left((1-\lambda)\left(\bar{e}_{J} z h-\Gamma_{j}(z)\right), 1-h\right) \\
\text { s.t. } h & \in[0,1]
\end{aligned}
$$

Both maximization problems are well-defined (maximization of continuous function over a compact set). Since the constraint correspondence is continuous, by the (standard) 
maximum theorem $V_{J}^{R}(d ; z, \kappa)$ is continuous in $d$ for $d \leqslant \bar{e}_{J} z-\kappa$ and is u.s.c. everywhere. As the constraint set is decreasing (shrinking) in $d$, so is the value function. Since $V_{J}^{B}(d ; z, \kappa)$ is constant in $d$ and $V_{J}^{R}(d ; z, \kappa)$ is decreasing in $d$, they satisfy the SCP.

Define the value function as $V_{J}(d ; z, \kappa)=\max \left\{V_{J}^{R}(d ; z, \kappa), V_{J}^{B}(d ; z, \kappa)\right\}$. Note that it is always finite since the value of non-repayment is finite, and is (weakly) decreasing since the value of repayment is decreasing.

\section{A2. Pricing Function}

The bond price is

$$
q_{j}\left(d^{\prime}, z\right)=\left(1-\theta_{j}\left(d^{\prime}, z\right)\right) q^{b}+q^{b} \theta_{j}\left(d^{\prime}, z\right) E\left(\frac{\Gamma_{j+1}\left(z^{\prime}\right)}{d^{\prime}+\kappa^{\prime}}\right)
$$

where the expectation is conditional on declaring bankruptcy and the current state $z$.

We follow the convention that a household, who is indifferent between repaying and not repaying its debt, does not declare bankruptcy. Combined with the single crossing property of $V^{R}$ and $V^{B}$, this implies that $\left(1-\theta_{j}\left(d^{\prime}, z\right)\right)$ is an u.s.c. decreasing step function of $d^{\prime}$.

Since $E\left(\frac{\Gamma_{j+1}\left(z^{\prime}\right)}{d^{\prime}+\kappa^{\prime}}\right)$ is a decreasing u.s.c. function of $d^{\prime}$ (and lenders can never receive more than $\left.d^{\prime}\right), q_{j}\left(d^{\prime}, z\right)$ is a decreasing u.s.c. function of $d^{\prime}$ for each $z$.

Claim 1. $q_{j}\left(d^{\prime}, z\right) d^{\prime}$ has an irrelevant tail.

Proof. We provide the proof for a simpler environment, and then explain how the proof can be extended to our environment. Suppose that financial intermediaries have priority claim to the proceeds of garnishment of bankrupt households. In this case, the amount garnished first goes to repay the lenders, and unexpected expenses are partly covered only after lenders are repayed. The price is:

$$
q_{j}\left(d^{\prime}, z\right)=\left(1-\theta_{j}\left(d^{\prime}, z\right)\right) q^{b}+q^{b} \theta_{j}\left(d^{\prime}, z\right) E\left(\frac{\min \left\{\Gamma_{j+1}\left(z^{\prime}\right), d^{\prime}\right\}}{d^{\prime}}\right)
$$

where the expectation is conditional on declaring bankruptcy and the current state $z$.

Since $V_{j+1}^{R}(d ; z, \kappa)$ and $V_{j+1}^{B}(z)$ satisfy the SCP for $\forall z, \kappa, \exists D$ such that the borrower defaults with probability 1 . Moreover, $\Gamma_{j+1}\left(z^{\prime}\right)<d$ for $\forall d>D, z^{\prime}$. Thus

$$
q_{j}\left(d^{\prime}, z\right)=\frac{q^{b}}{d^{\prime}} E\left(\Gamma_{j+1}\left(z^{\prime}\right)\right) \quad \text { for } \forall d^{\prime}>D
$$

and

$$
q_{j}\left(d^{\prime}, z\right) d^{\prime}=q^{b} E\left(\Gamma_{j+1}\left(z^{\prime}\right)\right) \quad \text { for } \forall d^{\prime}>D \quad \text { QED. }
$$

Unfortunately, in our environment $q_{j}\left(d^{\prime}, z\right) d^{\prime} \rightarrow q^{b} E\left(\Gamma_{j+1}\left(z^{\prime}\right)\right)$ from below as $d^{\prime} \rightarrow \infty$, 
because the lenders get increasing share of the garnishment as the face value of the debt increases.

We have to verify $\forall z, j \exists d_{0}$ such that $q_{j}\left(d_{0}, z\right) d_{0} \geqslant q^{b} E\left(\Gamma_{j+1}\left(z^{\prime}\right)\right)$. This holds for the parameter values used in this paper (as is illustrated by Figures 4). More generally, this condition requires that the magnitude and/or probability of expense shocks is small enough relative to the variation in $\Gamma_{j+1}\left(z^{\prime}\right)$ or transaction cost $\lambda$.

Lemma 1. If $q_{j}\left(d^{\prime}, z\right)$ is u.s.c. and $q_{j}\left(d^{\prime}, z\right) d^{\prime}$ has an IT, then

$$
M_{j}(z)=\max _{d^{\prime}}\left[q_{j}\left(d^{\prime}, z\right) d^{\prime}\right]
$$

is achieved.

Proof. Since $q_{j}\left(d^{\prime}, z\right) d^{\prime}$ has an IT, we can restrict the constraint set to $[0, D]$ for some large $D$. Solution exists since we are maximizing an u.s.c. function over a compact set.

QED

\section{A3. Household's Problem}

Define

$$
\begin{array}{r}
V_{j}^{R}(d ; z, \kappa)=\max _{d^{\prime}, h}\left[u\left(\bar{e}_{j} z h+d^{\prime} q_{j}\left(d^{\prime}, z\right)-d-\kappa, 1-h\right)+\beta E V_{j+1}\left(d^{\prime}+\kappa^{\prime}, z^{\prime}\right)\right] \\
\text { s.t. } \\
\qquad h \in\left[\max \left\{0, \frac{d+\kappa-d^{\prime} q_{t}\left(d^{\prime}, z\right)}{e_{j} z}\right\}, 1\right]
\end{array}
$$

and

$$
\begin{aligned}
V_{j}^{B}(d ; z, \kappa) & =\max _{h}\left[u\left((1-\lambda)\left(e_{j} z h-\Gamma\right), 1-h\right)+\beta E V_{j+1}\left(\kappa^{\prime}, z^{\prime}\right)\right] \\
\text { s.t. } & h \in[0,1]
\end{aligned}
$$

LEmma 2. If $q_{j}\left(d^{\prime}, z\right) d^{\prime}$ has an IT and $V_{j+1}\left(d^{\prime} ; z, \kappa\right)$ is decreasing in $d^{\prime}$, then age- $j$ household's problem (A1) is equivalent to maximizing the objective function over a compact set.

Proof. Since $q_{j}\left(d^{\prime}, z\right) d^{\prime}$ has an IT, $\exists d_{0}, D$ such that $q_{j}\left(d^{\prime}, z\right) d^{\prime} \leqslant q_{j}\left(d_{0}, z\right) d_{0} \quad \forall d^{\prime} \geqslant D$. Since $V_{j+1}\left(d^{\prime} ; z, \kappa\right)$ is decreasing in $d^{\prime}$, the value of the objective function at $\forall d^{\prime}>D$ cannot be greater than that at $d_{0}$. Also, $d^{\prime}<d+\kappa-e_{j} z$ cannot be feasible. As the constraint set is closed, and we can effectively bound it, we have a maximization over a compact set. QED

Claim 2. If $V_{j+1}(d)$, is u.s.c. and decreasing in $d$, and $q_{j}\left(d^{\prime}, z\right)$ is u.s.c. and $q_{j}\left(d^{\prime}, z\right) d^{\prime}$ has an IT, then $V_{j}^{R}(d ; z, \kappa)$ is u.s.c. and decreasing in $d$.

Proof. First, we show that $\exists \bar{D}$ such that age- $j$ household's problem (A1) for $d \in(-\infty, \bar{D}]$ involves maximizing an u.s.c. function subject to an u.h.c. non-empty valued constraint 
correspondence, and for $d \in(\bar{D}, \infty)$ the constraint correspondence is empty-valued. Then by generalized maximum theorem (see Berge (1963), page 116), $V_{j}^{R}(d ; z, \kappa)$ is u.s.c. on $(-\infty, \bar{D}]$. We set $V_{j}^{R}(d ; z, \kappa)=-\infty$ on $(\bar{D}, \infty)$, and hence $V_{j}^{R}(d ; z, \kappa)$ is u.s.c. everywhere.

Using lemma 1., we define $\bar{D}(z, \kappa)=e_{j} z+M_{j}(z)-\kappa$. It is obvious that the constraint correspondence in problem (A1) is non-empty valued iff $d \in(-\infty, \bar{D}(z, \kappa)]$.

Now note that the objective function

$$
u\left(\bar{e}_{j} z h+d^{\prime} q_{j}\left(d^{\prime}, z\right)-d-\kappa, 1-h\right)+\beta E V_{j+1}\left(d^{\prime}+\kappa^{\prime}, z^{\prime}\right)
$$

is u.s.c. in $\left(h, d^{\prime}\right)$. This follows from upper semi-continuity of $V_{j+1}(d ; z, \kappa)$ and the fact that a continuous strictly increasing function of an u.s.c. function is also u.s.c. together with upper semi-continuity of $q_{j}\left(d^{\prime}, z\right)$.

Since the objective function is an u.s.c. numerical function, and the constraint correspondence is u.h.c. and non-empty valued on $(-\infty, \bar{D}]$, we can apply the generalized maximum theorem (see Berge (1963), page 116) to conclude that $V_{j}^{R}(d ; z, \kappa)$ is u.s.c. in $d$ on $(-\infty, \bar{D}]$. Setting $V_{j}^{R}(d ; z, \kappa)=-\infty$ on $(\bar{D}, \infty)$, we guarantee that $V_{j}^{R}(d ; z, \kappa)$ is u.s.c. everywhere. And since both the objective function and the constraint correspondence in A1 are decreasing (shrinking) in $d, V_{j}^{R}(d ; z, \kappa)$ is decreasing in $d$.

Hence, $V_{j}(d), V_{j}^{R}(d), V_{j}^{B}(d)$ are all u.s.c. and decreasing in $d$ for $\forall z, \kappa, j=1, \ldots, J$. They satisfy the single crossing property, because (as for the case $j=J$ ) $V_{j}^{B}(d ; z, \kappa)$ is constant in $d$ and $V_{j}^{R}(d ; z, \kappa)$ is decreasing. This completes our backward induction argument and establishes the existence of equilibrium.

QED 
Figure 1. Histogram of 5-year Medical Shocks as Fraction of Average Annual Income, Germany and USA

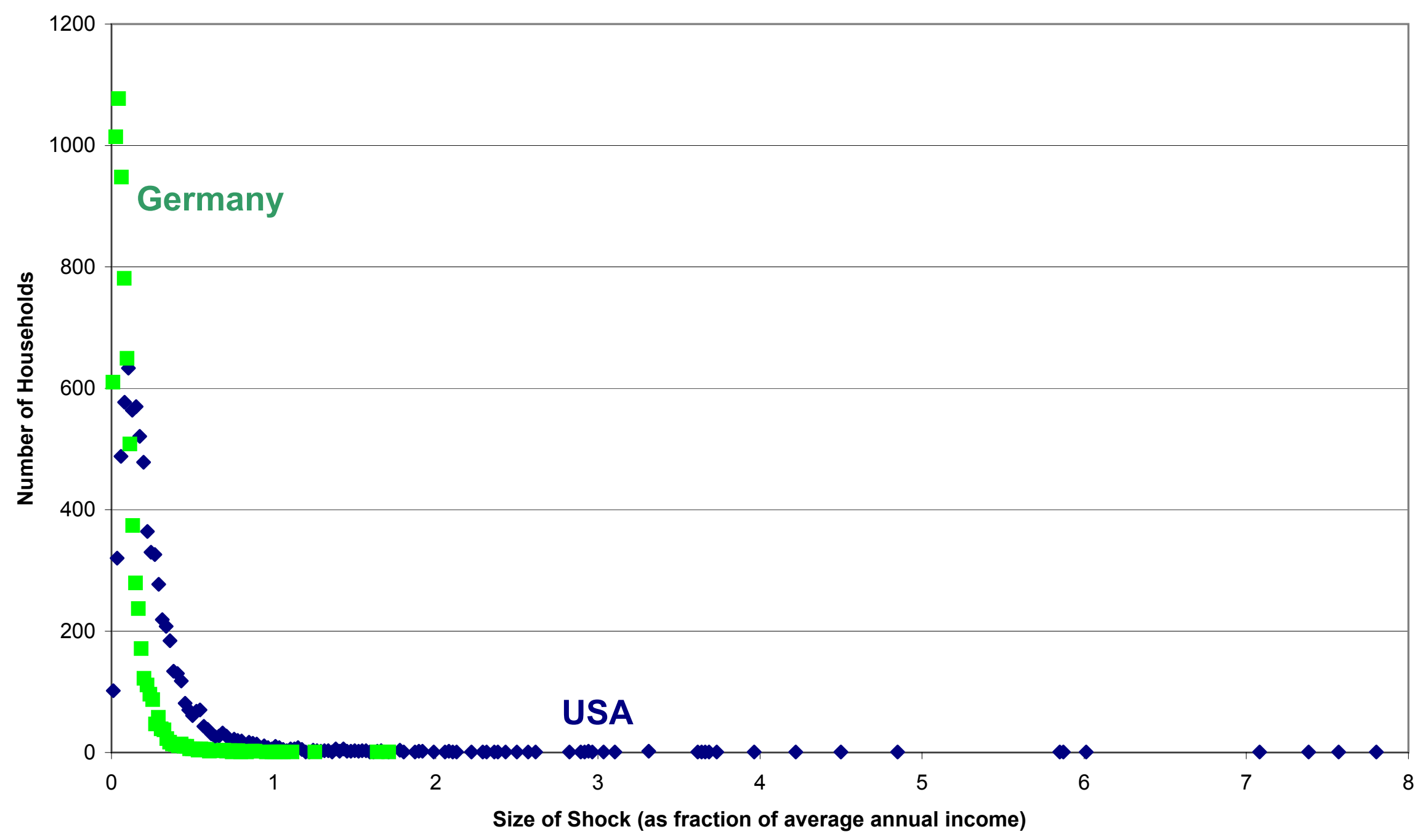


Figure 2. Private Bond Prices, Fresh Start

Benchmark Economy, Generation 1

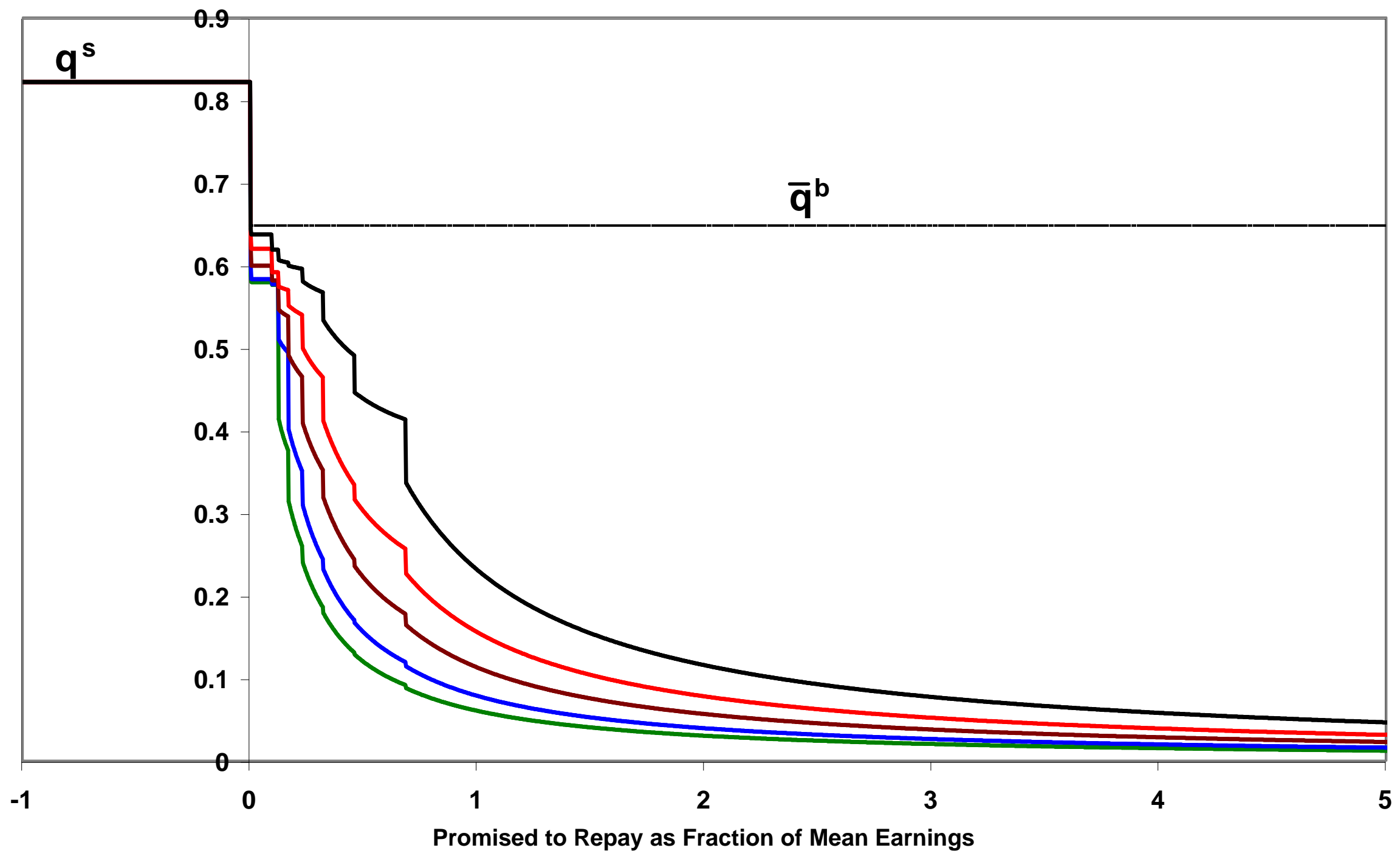


Figure 3. Private Bond Prices, No Fresh Start Benchmark Economy, Generation 1

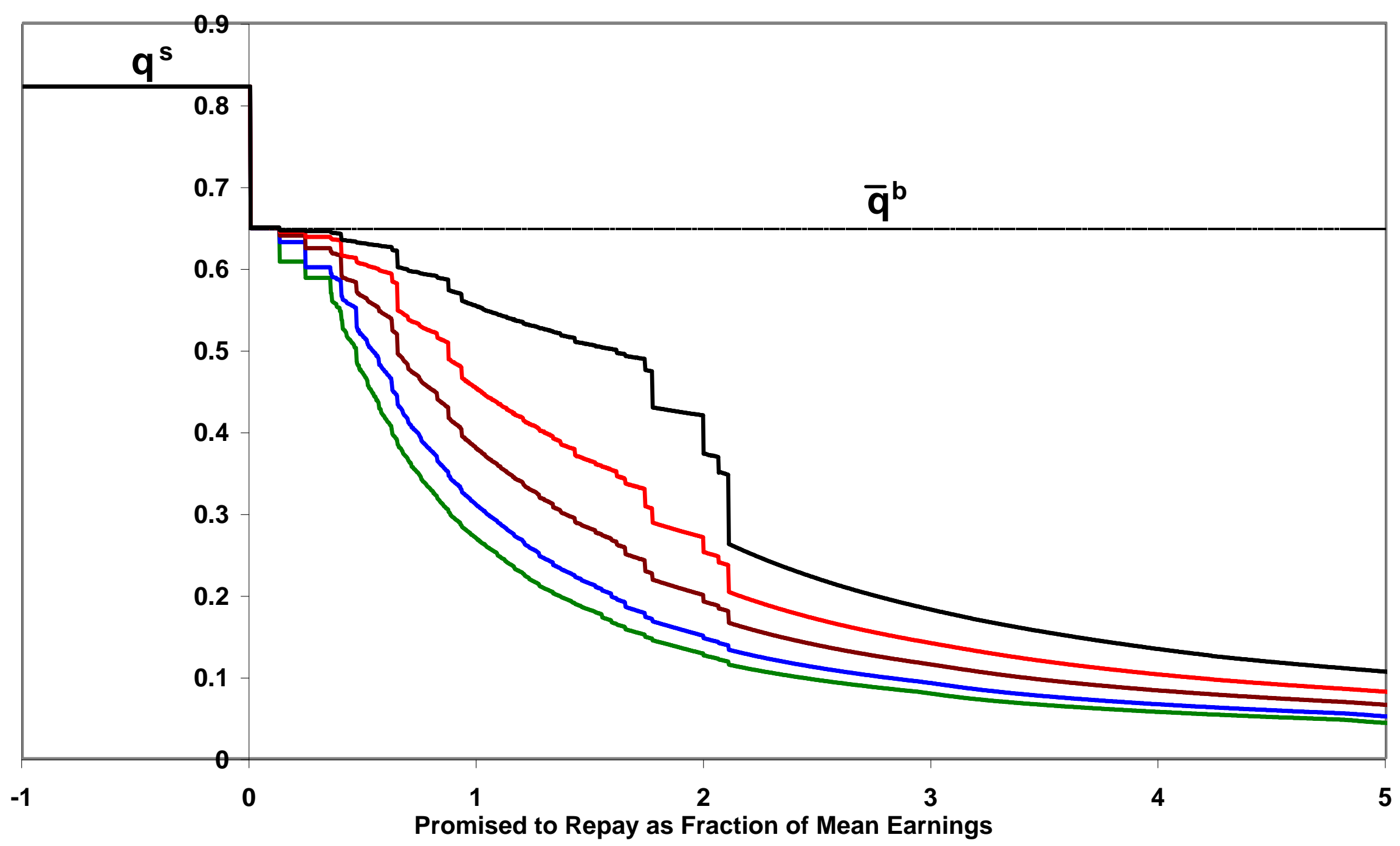


Figure 4. Borrowing Constraints, Fresh Start Benchmark Economy, Generation 1

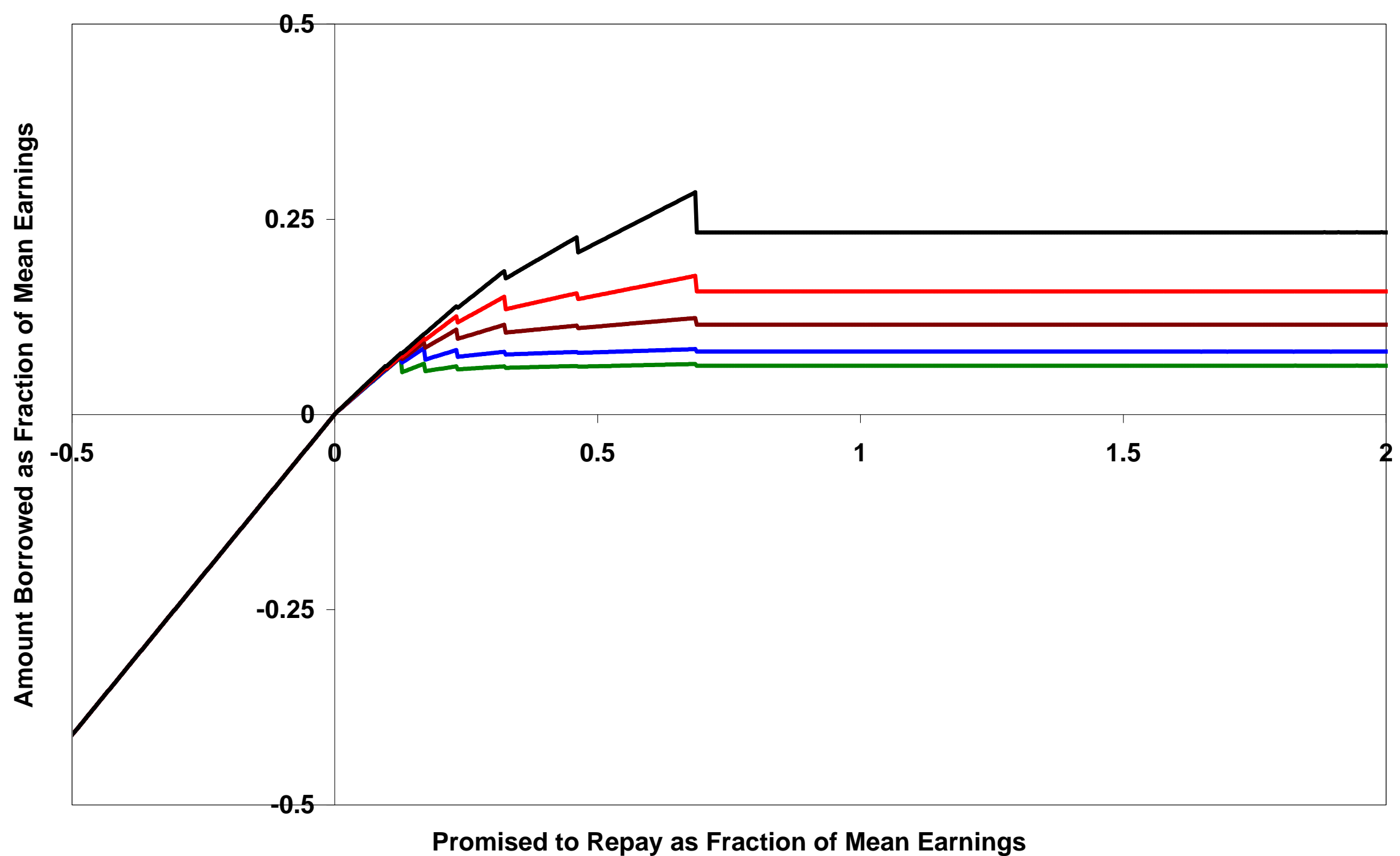


Figure 5. Borrowing Constraints, No Fresh Start

Benchmark Economy, Generation 1

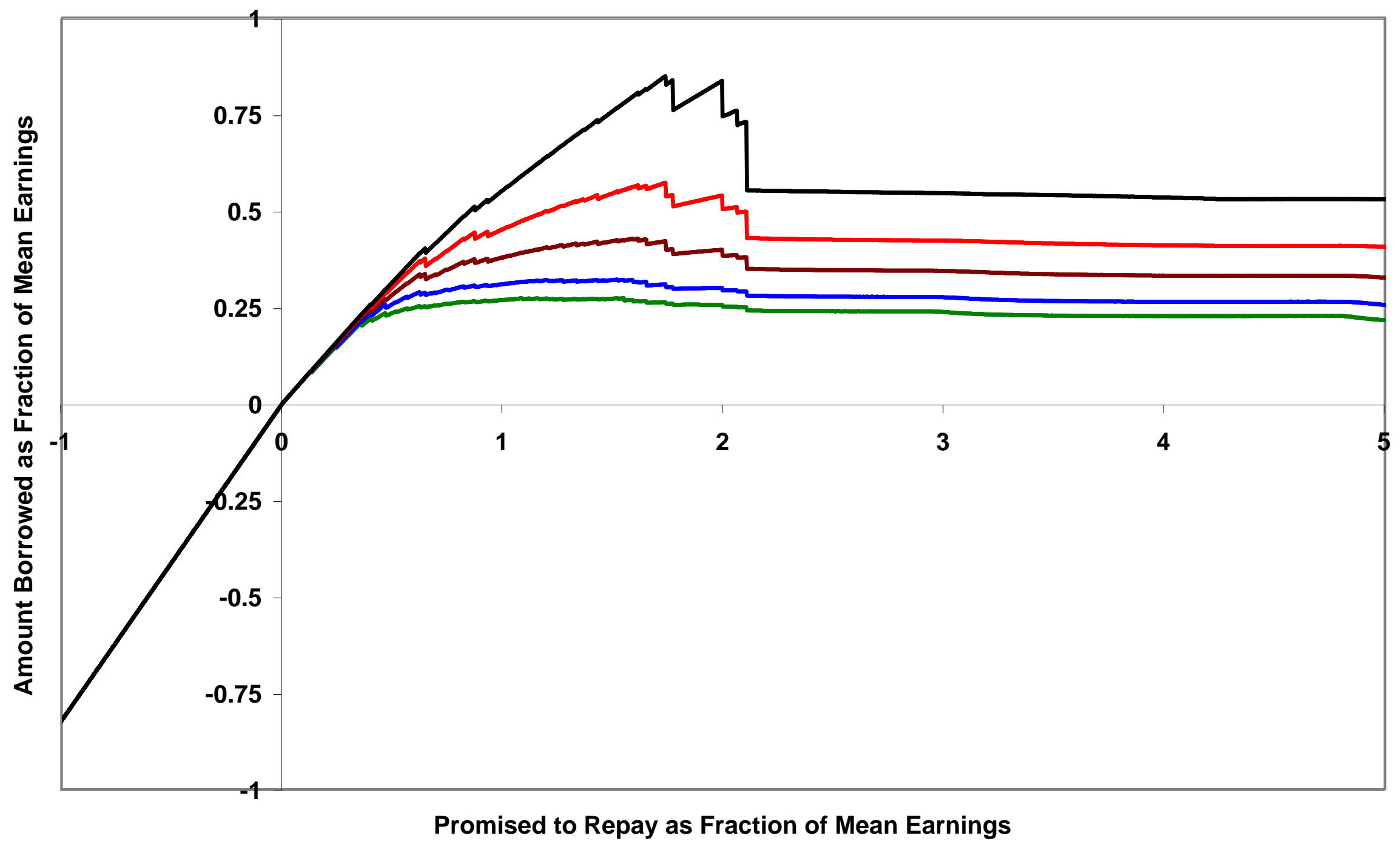

